\title{
Quatro Monografias Premiadas pela RSP
}

A bibliografia brasileira de Administração Pública será enriquecida, dentro em breve, com a publicação de quatro estudos da mais alta qualidade, selecionados no terceiro Concurso de Monografias sôbre Administração de Pessoal e seus Problemas Básicos, patrocinado pela Revista do Serviço Público. Resultaram da escolha efetuada por uma Comissão Especial que analisou os trabalhos inscritos, dentro de critérios preestabelecidos que determinaram a exclusão de vários dêles, portadores também de méritos indiscutiveis. Para êstes, porém, embora não incluídos entre os premiados, está prevista a possibilidade de ampla divulgação, através da Revista ou em separatas, conforme está sendo programado, dentro da orientação da DireçãoGeral do Departamento Administrativo do Pessoal Civil.

A repercussão do Concurso, tanto na imprensa em geral quanto nos circulos mais representativos dos servidores públicos e demais estudiosos de Administração, pode ser mensurada pelo número de notas publicadas e de cartas recebidas, notadamente considerando-se a especialização da matéria tratada.

O CONCURSO

As Instruções Reguladoras do Concurso foram publicadas inicialmente no Diário Oficial da Uniăo, em 10 de abril de 1970, e posteriormente pelos principais órgåos da imprensa não oficial que atingiram tôdas as regióes do País. Estavam expressas na Portaria n? 55 , do Diretor-Geral do DASP, que autorizou o empreendimento, estabeleceu suas finalidades, indicou o temário, estabeleceu normas para a inscrição e apresentação das monografias e instituiu um cronograma para a realização, além de fixar os prêmios a serem concedidos $e$ as demais normas para a classificação, julgamento e premiação.

Foram os seguintes os objetivos do Concurso: estimular pesquisas e análise, em profundidade, dos temas fundamentais da Administração de Pessoal que estão reclamando soluçōes práticas e urgentes, de interêsse imediato dos órgãos da Administração Direta e Indireta, no contexto global dos princípios e diretrizes da Reforma Administrativa; promover levantamento atualizado das deficiências, anacronismo, rotinas superadas ou das anomalias de qualquer espécie que perturbam, entravam e oneram o funcionamento dos órgãos integrantes do Sistema de Pessoal do Poder Executivo da União, ocasionando prejulzos, baixos coeficientes de produtividade, desperdicios ou ineficiêncla; oferecer contribulção - mediante diagnóstico exato e sugestão de medidas de correção das anomalias ou deficiências identificadas - para acelerar o ritmo de implantação da Reforma Administrativa $e$ atingir niveis mais elevados 
de racionalidade, melhores condições operacionals, economia e eficiência daquele sistema; captar e valorizar a contribuição técnica de diretores, chefes, assessôres, funcionários e estudiosos em geral, cujos estudos e experiência possam proporcionar sugestōes concretas e válidas à solução dos problemas de Administração de Pessoal.

\section{A COMISSÃO ESPECIAL}

Encerrada a inscrição das monografias, em 30 de setembro de 1970 , a direção da Revista passou a coordenar todos os contatos e providências necessárias, até que, através da Portaria $n$ : 336, do Diretor-Geral do DASP, fol designada a Comissão Especial, "incumbida de proceder ao estudo, julgamento e classificação dos trabaIhos inscritos" no Concurso de Monografias sôbre Administração de Pessoal e seus Problemas Básicos.

Publicada a Portaria no Diário Oficial de 13 de novembro, já no dia 17 do mesmo mês reuniu-se, em sua primeira sessão de julgamento, a Comissão Especial. Constituiram-na os seguintes membros: Coronel Octávio Pereira da Costa, Chefe da Assessoria Especial de Relações Públicas da Presidência da República; Dr. Antônio Fonseca Pimentel, Subchefe para Assuntos de Administração Geral do Gabinete Civil da Presidência da República; Prof. Paulo Vieira da Silva, Decano de Assuntos Administrativos da Universidade de Brasília; Prof. Edson Nery da Fonseca, Chefe do Departamento de Biblioteconomia da Universidade de Brasília; Dr. Corsíndlo Monteiro da Silva, Assessor-Técnico da Coordenação de Legislação de Pessoal do Departamento Administrativo do Pessoal Civil; Prof. Henrique Teixeira
Tamm, Coordenador de Educação Média da Secretaria de Educação e Cultura do Govêrno do Distrito Federal; e Prof. Araújo Cavalcanti, Diretor da Revista do Serviço Público.

PREMIADOS DE 1970

Concluidas as atividades da Comissão Especial e aprovadas as suas resoluções pelo Diretor-Geral do DASP, fol publicada no Diário Oficial de 21 de dezembro de 1970 , a Portaria no 371 , que homologava a concessão dos seguintes prêmios:

19. lugar - PREMIO DE Cr\$...... 7.000,00: Monografia n? 1, "Informática na Administração de Pessoal" Pseudônimo: THETANO; Autor: João Luiz Martins Ney da Silva;

2. lugar - PREMIO DE Cr\$ ...... 5.000,00: Monografia n? 4, "Um Programa de Desenvolvimento de Pessoal" Pseudônimo: DIADORIM; Autora: Maria da Imaculada Conceição Monteiro Machado;

3: lugar - PREMIO DE Cr\$ ...... 3.000,00: Monografia $n$ ? 9, "A Técnica da Comunicação na Redação Oficial" - Pseudônimo: PERO VAZ DE CAMINHA; Autor: José Augusto Nascimento Guerra; e

4: lugar - PREMIO DE Cr\$...... 2.000,00: Monografia no 6, "Manual das Relações Chefes/Subordinados" Pseudônimo: ALKINOH; Autora: Alice da Cunha.

Os prêmios foram entregues, em sessão solene, realizada no Auditório do DASP, às 15 horas do dia 15 de dezembro, com a presença dos quatro premiados, sob a presidência do Diretor-Geral do Departamento Administrativo do Pessoal Clvil, Dr. Glauco Lessa de Abreu e Silva. 


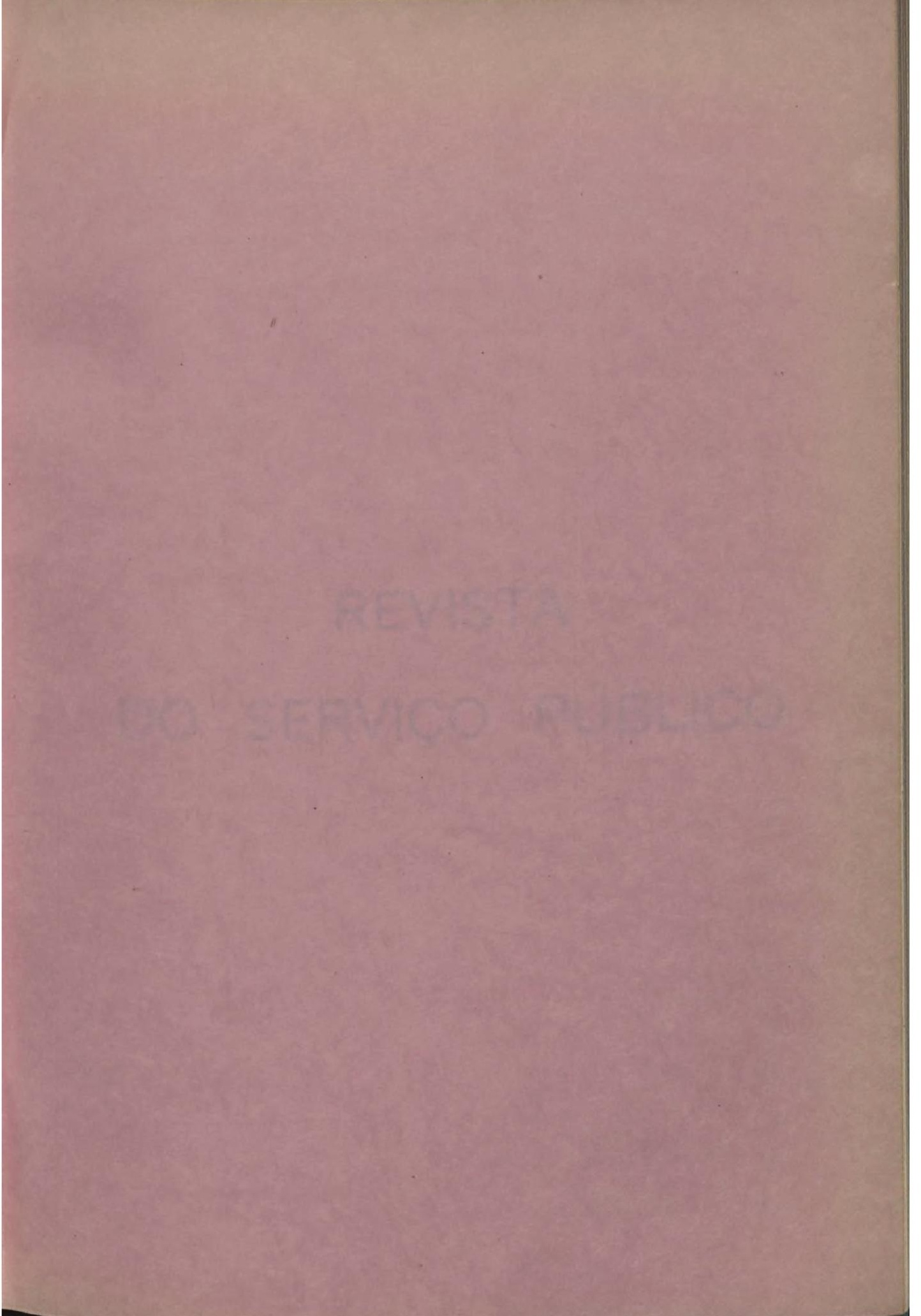




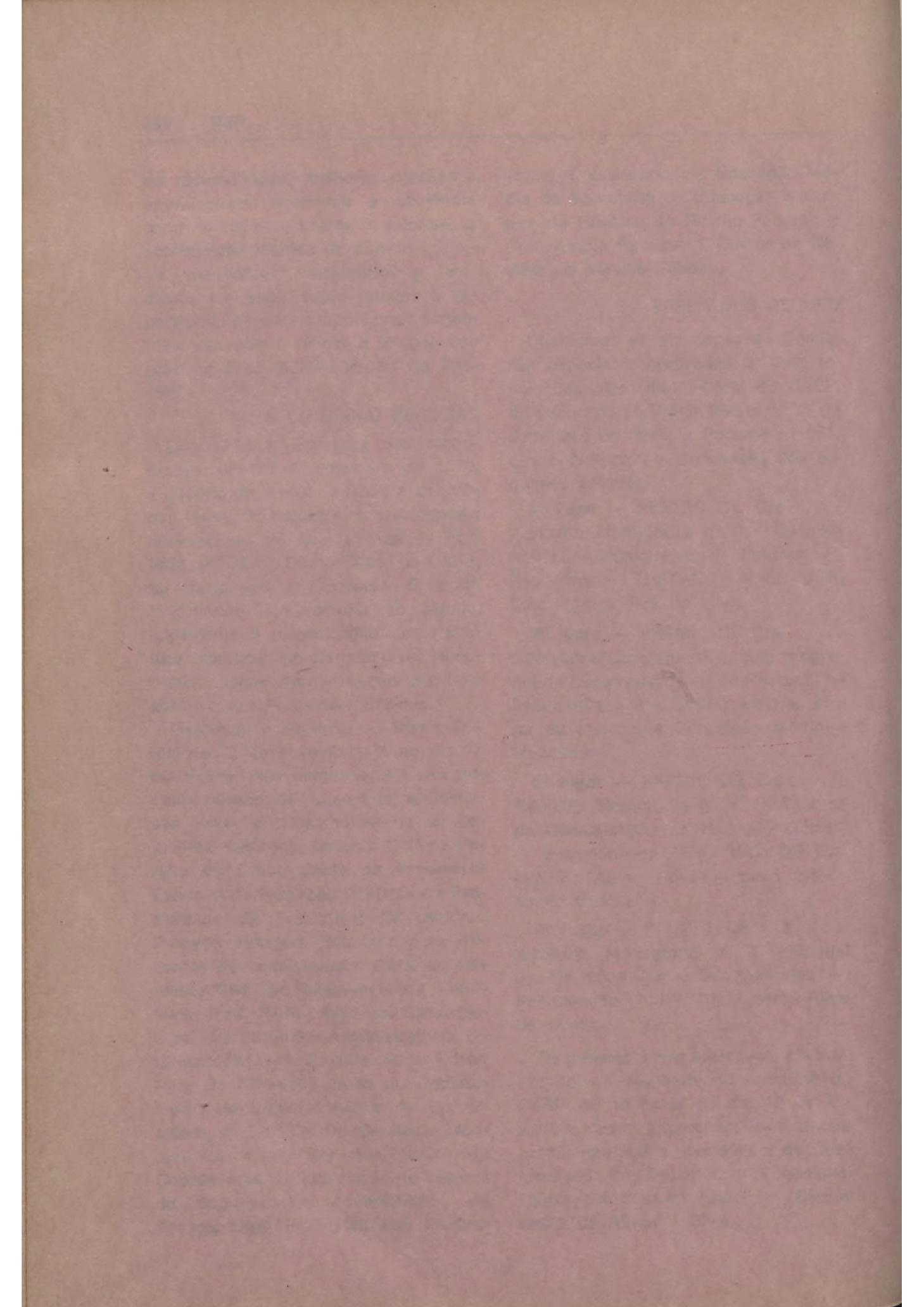

